\title{
LA CONCESIÓN (O DENEGACIÓN) DE LA LIBERTAD CONDICIONAL: LA ELABORACIÓN DE LAS RESOLUCIONES INTERLOCUTORIAS. UN ESTUDIO DE CASO EN ARGENTINA
}

\author{
THE GRANTING (OR REFUSAL) OF PAROLE: THE DEVELOPMENT OF \\ INTERLOCUTORY DECISIONS. A CASE STUDY IN ARGENTINA
}

\author{
Beatriz Kalinsky ${ }^{l}$ \\ Universidad de Buenos Aires \\ beatrizkalinsky@gmail.com \\ Argentina
}

\section{SUMARIO}

- Introducción

- Métodos

- Resultados

- La Ley 24660/96 de Ejecución Penal de la República Argentina

- Concesión o denegación de la libertad condicional.

- Dos casos de resoluciones interlocutorias y su análisis

- Conclusiones

- Referencias

\section{RESUMEN}

La autora se propone reflexionar sobre el instituto jurídico de la «libertad condicional» en Argentina como un momento de transición a la vida libre después de un periodo de encierro carcelario. Se describen incongruencias en la letra de la ley sobre ejecución penal de la Argentina (24.660/96 y sus modificatorias) así como entre la letra de la ley y su puesta en práctica. Se muestran dos resoluciones interlocutorias en las que se concede y deniega la libertad condicional. De inmediato, surge la pregunta sobre el criterio de comparación entre las relaciones sociales mantenidas por estas personas entre el contexto de encierro y el de libertad, ya que la libertad condicional se otorga cuando la conducta y el concepto en el encierro merecen una calificación satisfactoria, sin atender las variables de la realidad a la que se retorna. Se postula entonces la necesidad de reconocer otros factores que por ahora se ignoran, pero de indispensable importancia en la planificación de políticas públicas criminológicas.

\section{PALABRAS CLAVE}

Contextos, criterios de comparación, encierro, contextos, libertad condicional, resoluciones interlocutorias.

\begin{abstract}
This paper intends to consider legal institution of "probation" as a transition to the free life after a period of prison confinement. Inconsistencies in the letter of the law on criminal enforcement of Argentina (24.660/96 and its amendments) and between the letter of the law and its implementation are described. Are showed two interlocutory decisions which grant or deny probation. Immediately arises the question about the comparison criteria between social relations maintained by these people among the context of confinement and the other of freedom due that parole is granted when the conduct and the concept confinement deserve a satisfactory rating without addressing the free life variables. It is then proposes the need to recognize other factors that nowadays are ignored and are of indispensable importance in planning public policy criminology.
\end{abstract} 1 Antropóloga. Doctora por la Universidad de Buenos Aires. Docente e investigadora de la Facultad de Filosofia y Letras, Universidad
de Buenos Aires. Investigadora del Consejo Nacional de Investigaciones Científicas y Técnicas (Conicet) 


\section{KEYWORDS}

Benchmarks, Confinement, Comparison Criteria, Contexts, Interlocutory, Parole.

\section{INTRODUCCIÓN}

En Argentina la llamada «libertad condicional» es, en la actualidad, el periodo en que aquella persona que ha cumplido las dos terceras partes de una sentencia condenatoria a la que fue sometida dentro del marco constitucional de un estado de derecho y, teniendo informes favorables de las juntas de expertos penitenciarios correspondiente («juntas correccionales») vuelve a estar «en libertad» con determinados requisitos hasta el agotamiento de la condena, siempre y cuando haya sido solicitada por el propio preso o a través de su abogado defensor. ${ }^{2 \mathrm{y} 3}$

Dice la ley $24.660 / 96^{4}$ sobre la ejecución de la pena privativa de la libertad en el capítulo correspondiente:

\section{«Periodo de libertad condicional}

Art. $28^{\circ}$. El juez de ejecución o juez competente podrá conceder la libertad condicional al condenado que reúna los requisitos fijados por el Código Penal, previo los informes fundados del organismo técnico-criminológico y del consejo correccional del establecimiento. Dicho informe deberá contener los antecedentes de conducta, concepto, dictámenes criminológicos desde el comienzo de la ejecución de la pena. ${ }^{5} \mathrm{y}$, si correspondiere, del equipo especializado previsto en el inciso I del artículo $185 .^{\circ}$ de esta ley.

Art. 29 ${ }^{\circ}$ La supervisión del liberado condicional comprenderá una asistencia social eficaz a cargo de un Patronato de Liberados o de un servicio social calificado, de no existir aquel. En ningún caso se confiará a organismos policiales o de seguridad» (Código Penal de la Nación Argentina, 1984).

2 Así como el resto de las libertades que contempla la ley de ejecución penal argentina.

3 Los requisitos específicos están reiterados en cada una de las resoluciones interlocutorias, lo que nos exime de repetirlos en el cuerpo del texto.

4 Modificada el 12 de noviembre de 2004 y, nuevamente, en la ley 26.813, publicada en el Boletín Oficial del 16/01/2013.

5 En nuestro lugar de trabajo no existen juzgados de ejecución, por lo que estas decisiones las toman los jueces de sentencia, a veces los mismos que decidieron la condena del ahora preso. Existen tres juzgados nacionales de ejecución penal en la Ciudad Autónoma de Buenos Aires, competentes en ese distrito judicial.
En líneas generales, al periodo de libertad condicional se lo toma como una cuestión procedimental. No obstante, desde el punto de vista social, es un momento de fragilidad en un doble sentido: Por un lado, el paso del encierro a la libertad genera una conmoción emocional tanto en quien sale en libertad como en quienes lo reciben; por otro lado, resulta un momento en el cual la reincidencia está casi a la mano. (Clear, Rose y Ryder, 2001; Leverentz, 2001; Maruna, 2001). Si no se pueden dar algunas condiciones mínimas de carácter estructural, así como otras de índole comunitaria y personal, las intenciones de no recaer en el delito se vuelven en contra.

Si bien en Argentina algunos casos de un delito específico, como la violación, se repitieron durante la libertad condicional con una considerable repercusión mediática - haciendo que la opinión pública y los operadores jurídicos se ocuparan, solo en esta inflexión, del contenido y la justificación de los fallos interlocutorios que les habían concedido este derecho-, a la vez es cierto que en otros casos el regreso es exitoso. En otras situaciones, se vuelve a la cárcel por quebrantar alguna de las condiciones bajo las que se concedió la libertad condicional. De esta forma, desde el punto de vista de las políticas criminológicas, su importancia se ha hecho patente y ha entrado en la agenda pública como cuestión a plantear, diagnosticar y evaluar.

El objetivo que orienta este trabajo tiene relación con ciertas incongruencias dentro de la ley de ejecución penal, así como con algunos conflictos entre ella y las condiciones concretas de su aplicación. Se analizan algunas resoluciones interlocutorias como el estudio de casos y se establecen algunas conclusiones preliminares dentro de una investigación que se desarrolla en una provincia de la Patagonia norte, República Argentina. Esta se ejecuta en el marco de un proyecto mayor cuya finalidad es mostrar, en clave social, el proceso penal penitenciario - pospenitenciario y su incidencia en el ámbito individual (personal), familiar y comunitario, en términos generales.

\section{MÉTODOS}

La investigación es cualitativa, desde una perspectiva de descripción etnográfica densa, que usa diversas técnicas usuales en este tipo de indagaciones (entrevistas semiestructuradas 
o en profundidad, reconstrucción de historias de vida, grupos focales y observación participante, entre las principales).

Intentamos configurar un escenario múltiple y multidimensional donde estén contenidas las voces de los protagonistas. Se analizaron 15 casos en profundidad, 8 mujeres y 7 varones, a quienes se entrevistó en diferentes tiempos vitales en relación con la ejecución de la condena y su vida, ya en libertad, bajo la modalidad de «libertad condicional» $\mathrm{O}$ «libertad asistida» ${ }^{6}$. Estos diálogos se establecieron con personas liberadas de quienes ya se conocía el periodo de encierro, con quienes cumplían la mitad de su libertad condicional y con quienes estaban por finalizarla. La edad promedio de los hombres fue de 30 años y de las mujeres, 27 años. Se obtuvieron diferentes resultados: algunos siguieron en libertad condicional hasta firmar su libertad definitiva; otros volvieron a la cárcel y se retomó contacto con ellos en situación de encierro; también se registró un suicidio y hubo un caso calificado como «paradero desconocido» ${ }^{7}$.

\section{RESULTADOS}

La investigación se desarrolló en la zona norte de la Patagonia Argentina entre 2012 y 2015. Fue financiada en diversas etapas por el Consejo Nacional de Investigaciones Científicas y Tecnológicas (Conicet) y la Secretaría de Ciencia y Técnica de la Universidad de Buenos Aires. A modo de hipótesis, se planteó que el instituto jurídico de la «libertad condicional» es también un proceso cognitivo, emocional y moral, desde el punto de vista de quienes no conforman el sistema jurídico-penal, donde se darán, o no, las condiciones necesarias (comunitarias, familiares, personales, económicas, institucionales, laborales y educativas) para un regreso a la vida libre. Caso contrario, se volverá a instalar el plan vital del delito para volver a una identidad previa en la que priman las acciones delictivas y un posible retorno a la cárcel.

$6 \mathrm{La}$ "libertad asistida" es un instituto que entra en funcionamiento cuando la persona ha sido declarada reincidente, de manera que puede abandonar la casa favorecida con este derecho seis meses antes del agotamiento de la pena a la que ha sido sometida.

7 En realidad, la mujer en mención solia pedir limosna con sus hijos a cuestas los sábados y domingos a la hora de la misa en la catedral de la ciudad. Se conversó con ella, pero la institución que debía "ubicarla" y entrevistarla para ver sus condiciones de vida en ese momento, no lo logró. Las misas se celebraban en dias y horarios prestablecidos.
No debiera responsabilizarse solo a la persona que está bajo estas condiciones cuando vuelve a delinquir, ya que hay factores, variables, y estamentos fuera de su alcance. Esto se daría porque carece de información acertada y no existen fuentes de guía genuinas que brinden los recursos necesarios para afrontar esta nueva situación, especialmente en el cumplimiento de condenas largas consideradas así desde los cinco años en adelante-, dado el rápido cambio social, cultural y tecnológico que experimentan las sociedades en la actualidad. La persona en libertad condicional solo tiene una porción de responsabilidad, quizá la menor y a la vez la más endeble, por lo que la sociedad y el Estado deben proporcionar las herramientas necesarias y suficientes para resolver la gran cantidad de problemas que reporta el regreso a la vida libre. Lamentablemente, estas responsabilidades no se plantean de esta forma, porque tanto la sociedad como el Estado se desentienden de las personas en «libertad condicional», dejando a la suerte $\mathrm{o}$, por el contrario, planteándose un determinismo esencialista sobre el futuro de aquellos que habrían «elegido» una trayectoria vital delictiva - algo así como «si es ladrón, lo será para siempre y no vale la pena concentrar recursos en ellos»o, desde el punto de vista comunitario, «estos que caen a la cárcel vuelven igual o peor que antes y generan demasiados problemas de los que no podemos hacernos cargo, ya que apenas lidiamos con los nuestros»- ${ }^{8} \mathrm{El}$ regreso o la reintegración no solo deberían referirse a la ausencia de actividad delictiva, sino también debería denotar las causas subyacentes que impiden satisfacer las necesidades que conducen a la reincidencia.

Algunos casos de resoluciones interlocutorias ${ }^{9 y 10}$

8 Estas frases fueron dichas en las numerosas entrevistas de campo que se aplicaron en barrios criminalizados, producto del alto porcentaje de vecinos que iban y venían de las cárceles y por el alto grado de vigilancia formal de la que eran objeto. Dada la fragilidad de los lazos sociales de estas comunidades, el control informal ejercido por las instituciones intermedias habia colapsado. (diario de campo en junio de 2012, abril de 2013, enero de 2014).

9 Se excluyeron los datos que, eventualmente, podrían conducir a la identificación de las personas y los lugares.

10 Las citas bibliográficas pertenecen al original. Agradecemos al Dr. Daniel Cesano por su gentil y desinteresada colaboración que finalmente dio forma a este artículo. 


\section{Caso A}

\section{RESOLUCIÓN INTERLOCUTORIA N. ${ }^{\circ} \mathbf{X X}$ $/ 2013$}

XXX (nombre de la ciudad), VEINTIUNO (21) DE FEBRERO DE DOS MIL TRECE

\section{VISTOS}

Estos autos caratulados «XXX s/ Ejecución de pena privativa de libertad», Expediente $\mathrm{N}^{\mathrm{o}}$ XXX, del Registro del este Juzgado de Ejecución Penal de 1. ${ }^{a}$ Nominación.

\section{CONSIDERANDO}

I. Que a fs. 281, el interno XXX, argentino, nacido el día veinticuatro de mayo de mil novecientos ochenta, hijo de XXX y de XXX, Prio. N. ${ }^{\circ}$ XXX, sección A.G, Leg. $N^{\circ}$ XXX, solicita se le conceda el beneficio de la Libertad Asistida (art. 54 de la Ley 24.660).

II. Que requeridos los correspondientes informes glosados a fs. 282-287 se ordena el traslado a las partes (fs. 288 vta.).

A fs. 289-290, el Sr. Fiscal Correccional de $1^{\circ}$ Turno, XXX, tras examinar las constancias de autos, concluye dictaminando lo siguiente: «(...) estima el Suscripto que no existen, hasta el presente, antecedentes de los cuales pueda inferirse que el egreso del condenado pueda llegar a constituir un grave riesgo para sí o para la sociedad... esta Fiscalía entiende que estarían dados todos los requisitos (objetivos y subjetivos) para que XXX acceda al beneficio de la Libertad Asistida... bajo las condiciones impuestas por el art. 55 de la Ley 24.660 más lo que V.S. estime prudente, conforme con su elevado criterio (...)».

A su turno, el Sr. defensor del interno, XXX, a fs. 294, manifiesta: «....esta defensa, compartiendo el criterio del Sr. Fiscal preopinante, concluye que XXX se encuentra en condiciones de acceder al beneficio solicitado toda vez que ha cumplido con los requisitos establecidos por la ley, y no es posible inferir que a su egreso pueda constituir un grave riesgo para sí, ni para la sociedad (...)».

III. Que ingresando al análisis de lo peticionado, considero que la libertad asistida que solicita el interno debe ser concedida.

Para llegar a tal conclusión habré de analizar si, en el presente caso, se verifican las exigencias establecidas por la ley para poder acceder al instituto que se pretende.

Cuatro son los requisitos que tornan operativo el acceso a la libertad asistida: uno positivo y los tres restantes negativos (cfr. Pérez y Novoa, 2007, p. 1291; y López y Machado, 2004, p. 183 y ss.).

El requisito positivo (en el sentido en que la ley está indicando cuál es la circunstancia debida para su viabilidad) consiste en el cumplimiento de la exigencia temporal: El interno estará en condiciones de acceder al instituto "seis meses antes del agotamiento de la pena». En el presente caso, teniendo en cuenta el nuevo cómputo oportunamente efectuado por la Cámara en lo

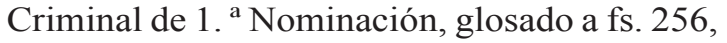
XXX cumple el total de la condena impuesta el día $04 / 08 / 2013$, por lo que a partir del día $04 / 02 / 2013$ [error en el original], le restan cumplir seis meses para el agotamiento de su pena; motivo por el cual, desde una perspectiva temporal, ya se encuentra en condiciones de acceder al régimen que solicita.

Los requisitos negativos (entendidos de este modo pues indican extremos que no deben verificarse para su procedencia) son: a) No presentarse la excepcionalidad negativa prevista por la norma y consistente en que su egreso anticipado constituya grave riesgo para sí o terceros; b) que no se le haya aplicado la reclusión por tiempo indeterminado como accesoria de la última condena (artículo $52^{\circ}$ del CP) y c) que no esté condenado a pena perpetua.

Destaco que en este caso no debo evaluar el requisito negativo derivado del artículo $56^{\circ}$ bis de la ley 24.660. Ello es así por cuanto, teniendo en cuenta la fecha de comisión de los hechos por los que purga pena, la ley 25.948 no resulta aplicable por tratarse de una norma posterior más gravosa; en los términos del artículo $18^{\circ}$ de la Constitución Nacional. No obstante ello aclaro que la criminalidad atribuida a XXX (robo agravado por el uso de arma de fuego) no se encuentra entre las figuras que enumera el citado artículo $56^{\circ}$ bis de la ley de ejecución de la pena privativa de la libertad.

Retornando al análisis de los requisitos exigibles, corresponde señalar que, en el caso que examino, el penado, si bien es reincidente, no se le hizo aplicación del artículo $52^{\circ}$ del 
Código Penal, por no darse los presupuestos que dicha norma exige (accesoria de tiempo indeterminado por varias reincidencias con distintos años de prisión).

Además, ha sido condenado a una pena temporal.

Resta analizar el recaudo negativo más importante; a saber, que el egreso del interno no constituya un grave riesgo para sí o para la sociedad.

Esta exigencia requiere un análisis pormenorizado, que evidencie distintas aristas que deben ser dilucidadas. En efecto:

En primer término, se debe afrontar un posible inconveniente de orden constitucional en lo que se refiere a la concreta aplicación de la exigencia. Ello es así por cuanto el supuesto y futuro riesgo social que puede representar la soltura de un condenado "constituye un elemento de ponderación puramente subjetivo» que puede aproximarse a un derecho penal de autor (López y Machado, op. cit., p. 184).

En este sentido, no faltan opiniones que postulan directamente la inconstitucionalidad del recaudo (cfr. Colombo, 2004, p. 86). Por mi parte, siguiendo la doctrina de nuestro máximo tribunal federal, antes de llegar a una declaración, el juez debe tratar de darle al precepto que se cuestiona una interpretación compatible con la Constitución; es decir, las leyes han de ser interpretadas en el sentido más favorable a su validez (Fallos: 285:60; 292:211; 296:22; entre otros).

Sentado ello, habré de coincidir con la postura hermenéutica señalada por López y Machado, en el sentido que este requisito negativo debe interpretarse en función de la nota de concepto: «Se valora la calificación conceptual a la que se refiere el art. $101^{\circ}$, denegando el acceso al instituto a todos aquellos condenados que, fundadamente, registren una desfavorable posibilidad de adecuada reinserción social» (op. cit., p. 186).

A diferencia «del riesgo o la peligrosidad en abstracto, el negativo registro conceptual posee un sustento objetivo constituido por la evolución evidenciada dentro del tratamiento de reinserción social aplicado al condenado. Por otra parte, encuentra asidero en lo previsto por el art. $104^{\circ}$ (y $68^{\circ}$ del anexo IV del decreto 344/2008), en cuanto establece que la nota conceptual servirá de base para la concesión de la libertad asistida» (López y Machado, op. cit., pp. 186-187. El agregado entre paréntesis me corresponde).

Analizados los informes elaborados por la administración penitenciaria y glosados a fs. 282/287, se puede observar que:

Tal como se desprende del informe de seguridad de fs. 282, el interno XXX ostenta actualmente una calificación de conducta «ejemplar» diez (10), la cual ha mantenido desde el 01/07/2010.

A lo largo de su institucionalización, XXX fue pasible de siete (7) procedimientos disciplinarios computables. Este extremo, sin embargo, en el caso, no tiene entidad suficiente para empañar el requisito que evalúo. Ello es así toda vez que, en un periodo de institucionalización de poco más de nueve años, dichas infracciones no son reveladoras de un desapego a las normativas institucionales, sino más bien constituye episodios aislados. Desde otra perspectiva, ninguna de las infracciones ha sido grave.

A fs. 285 vta., el área seguridad informa: " (...) interno que si bien en este último periodo se vio opacado por una corrección disciplinaria (en referencia a la infracción media consistente en no respetar las normas establecidas durante el goce de las salidas transitorias, al no regresar al establecimiento penitenciario). Una constante en su proceso de institucionalización fue la predisposición en cumplimentar las pautas de la normativa vigente. Además de ello, históricamente no ha evidenciado problemas y/o dificultad alguna para con sus iguales, manteniendo en líneas generales una conducta correcta y respetuosa».

En relación con esta deserción del periodo de prueba, tengo en cuenta que el penado no fue detenido con motivo de una nueva conducta ilícita, sino en el marco de un allanamiento, dispuesto en otro procedimiento, el cual dio resultado negativo (fs. 206 vuelta).

A la fecha y desde agosto del 2012, el interno se encuentra incorporado a la fase de confianza del régimen de progresividad y registra concepto «Bueno».

La nota conceptual evidencia una evolución positiva del interno (artículo $101^{\circ}, 2{ }^{a}$ disposición, ley 24.660). 
A dicha calificación, además, la juzgo como debidamente fundada en los diversos informes glosados.

Desde el área laboral, expresan que entre « (...)el día 01/01/07 hasta el día 27/12/10 participó del programa laboral en diversos sectores acorde a las fases del tratamiento que fue transitando. Luego es trasladado a la Unidad Abierta de XXX. A su reingreso, desde el día 13/06/12, se desempeñó en el Taller de Mimbrería hasta el día 12/4/2012, actividad que desarrolló (...) hasta el día 31/7/12, momento en que se efectúa un cambio laboral en el sector de obras y mantenimiento, mereciendo concepto bueno en la nueva tarea desempeñada».

Desde el área educativa, manifiestan que « (...) ingresó con el Nivel Primario incompleto. A lo largo de su detención, desde el año 2005 al 2011, participó del programa educativo formal y de actividad coprogramática, logrando alcanzar el segundo ciclo del Plan Fines. En el correspondiente ciclo lectivo 2012, desde su ingreso manifestó no querer continuar con la escolaridad formal hasta recuperar su libertad»».

Desde las áreas técnicas, Psicología informa: «XXX abordó aspectos personales vinculados a su historia de vida y de relación que lo habría posicionado ante situaciones de riesgo personal y social, derivando en sus procesos de prisionalización (...). Pudo reflexionar sobre las dificultades presentadas (...) donde habría primado el paso al acto por sobre otros mecanismos reflexivos, pudiendo posicionarse desde un lugar más maduro, realizando una revisión crítica de su accionar trasgresor». El servicio social expresa en su informe: « (...) es acompañado por su actual pareja, quien se encuentra en periodo de gestación, por lo que recibe asesoramiento respecto a las gestiones para realizar el reconocimiento de este nuevo descendiente (...)». Se consigna, además, que, en el caso de recuperar la libertad, el penado ha manifestado como proyecto laboral insertarse en rubro plomería y establecer residencia junto con su pareja, actual referente afectivo.

Al valorar los informes de las distintas áreas, el Organismo Técnico Criminológico manifiesta: «Se trata de un sujeto en el que su matriz de aprendizaje ha estado enraizada en pautas no aceptadas socialmente, y que su modelo de elaborar y organizar sus prácticas se encuentra determinado por la realización de actividades tanto delictivas como trasgresoras, sin que se pueda soslayar el ambiente carencial y contradictorio en el que se desarrolló su proceso de socialización, adicionándose a este los espacios de confinamiento a los que estuviera expuesto desde temprana edad (...). En este proceso de institucionalización (...) no presentó dificultades en el acatamiento a la normativa disciplinaria, condición que sostuvo prácticamente por un periodo de dos años cuando estuvo alojado en unidad abierta de autodisciplina hasta su deserción de la misma. En cuanto a los programas de tratamiento a nivel laboral realizó diversas fajinas y tareas que le posibilitaron la incorporación de algunos aprendizajes; sin embargo, se observa que, ante su reincorporación al periodo de tratamiento, una vez excluido del periodo de prueba, no demostró responsabilidad en las actividades encomendadas, razón por la que se efectúa cambio de tarea, llegando a reposicionarse positivamente en este programa.

Al presente, se encuentra haciendo tareas en el Sector de Exposición y Venta (...). Lo mencionado anteriormente se pondera como una fortaleza adquirida en este contexto, ya que durante los tiempos que se mantuvo en libertad, carecía de este tipo de hábitos (...)».

Sobre tal base de análisis, respecto de un interno que ha alcanzado cierta estabilidad conductual a lo largo de toda su institucionalización (manifestado en las notas de conducta registradas), que ha mantenido contacto con los programas laborales y educativos, que ha tenido contención familiar, del mismo grupo que lo recibirá cuando se produzca su egreso y que manifiesta proyectos alternativos a lo trasgresor, no puedo fundar, razonablemente, la existencia del grave riesgo que, excepcionalmente, permite negar este instituto; en los términos del artículo $54 .^{\circ}$ de la ley 24.660.

No puedo dejar de analizar un aspecto de las conclusiones emitidas por el organismo técnico criminológico recién trascriptas. Me refiero a la matriz de aprendizaje, enraizada en pautas trasgresoras. Indudablemente, esta valoración no puede soslayarse.

Sin embargo, considero que el mismo no tiene entidad para fundar la existencia del grave riesgo, por una conjunción de razones empíricas y jurídicas que paso a señalar: 
Por una parte, indudablemente, estas pautas de aprendizaje pueden tener incidencia en la criminogénesis. Sin embargo, tal apreciación no puede ser valorada con una perspectiva puramente determinista; concepto este, por lo demás, altamente discutible a nivel criminológico (cfr. Hollin, 2011, pp. 194-195). Es que, proceder de tal manera resulta incorrecto jurídicamente, porque importaría cancelar toda posibilidad de evolución personal positiva como consecuencia del tratamiento. Y esto es, ni más ni menos, que desoír el mandato constitucional establecido por el artículo 10 , apartado $3^{\circ}$, del Pacto Internacional de Derechos Civiles y Políticos, con jerarquía constitucional (artículo 75 , inciso $22,2^{\mathrm{a}}$ cláusula, de la Constitución Nacional), que fija los objetivos de la ejecución penitenciaria (cfr. Cesano, 2009, p. 41 y ss.).

De otro costado, aun quienes comulgan con las teorías del aprendizaje no dejan de señalar que, a partir de ellas, es posible elaborar estrategias de intervención que pueden insertarse en el tratamiento penitenciario. Así Clive Hollin (2011) señala que tales intervenciones pueden corporizarse en ayudas para quien delinquió, tendentes a mejorar sus habilidades sociales, «como sucede en el entrenamiento en destrezas sociales y (...) para la resolución de problemas (...)» (cfr. ibid., p. 507). Y en esta dirección incidencia del tratamiento-, el propio informe criminológico que evalúo, tras sintetizar ciertos logros alcanzados por el interno en las áreas laboral y educativa, caracteriza a los mismos como sintomático de «una fortaleza adquirida en este contexto (de encierro), ya que durante los tiempos que se mantuvo en libertad carecía de este tipo de hábitos» (fs. 287).

IV. Por todo lo expuesto, estimo que la petición formulada por el interno debe ser acogida, debiendo otorgarse a XXX, Legajo $\mathrm{N}^{\mathrm{o}} \mathrm{XXX}$, la libertad asistida bajo las condiciones que deberá cumplir hasta el agotamiento de la pena (04/08/2013), so pena de serle revocado el beneficio:

1. $\left.{ }^{\circ}\right)$ Residir en XXX de esta ciudad de XXX; debiendo comunicar a este Juzgado de Ejecución Penal de $1^{\mathrm{a}}$ Nominación en forma inmediata cualquier cambio de domicilio, bajo apercibimiento de revocación (artículos 15 , C.P. y 35 bis, inciso $5^{\circ}$, C.P.P.).

2. $\left.{ }^{\circ}\right)$ Abstenerse de consumir bebidas alcohólicas o utilizar sustancias estupefacientes.
3. ${ }^{\circ}$ ) Adoptar en el plazo de quince días, oficio, arte, industria o profesión; y acreditar ese extremo ante el Departamento de Reinserción Social del Liberado.

4. $\left.{ }^{\circ}\right)$ No cometer nuevos delitos.

5. ${ }^{\circ}$ ) Someterse al cuidado del Departamento de Reinserción Social del Liberado - Ministerio de Seguridad, Gobierno de la Provincia-, organismo que deberá informar a este juzgado cualquier incumplimiento en que incurriese el interno respecto de sus obligaciones de comparendo y velar por la inclusión sociolaboral del mismo.

Todas estas condiciones regirán hasta el vencimiento de la pena privativa de la libertad impuesta (04/08/2013), so pena de serle revocado el beneficio.

En razón de todo lo expuesto, de conformidad con lo dictaminado por el Sr. Fiscal Correccional, oída que fue el Sr. Asesor Letrado $\mathrm{y}$ analizados los informes administrativos, SE RESUELVE:

I. CONCEDER a XXX, Legajo N. ${ }^{\circ} \mathrm{XXX}$, de condiciones personales ya filiadas, la LIBERTAD ASISTIDA (art. 54 de la Ley Nacional n. ${ }^{\circ}$ 24.660), bajo las siguientes condiciones:

1. $\left.{ }^{\circ}\right)$ Residir XXX de esta ciudad, debiendo comunicar a este Juzgado de Ejecución Penal de 1. ${ }^{\mathrm{a}}$ Nominación en forma inmediata cualquier cambio de domicilio, bajo apercibimiento de revocación (artículos 15. , CP y $35 .^{\circ} \mathrm{Bis}$, inciso $\left.5 .^{\circ}, \mathrm{CPP}\right)$.

$\left.2 .^{\circ}\right)$ Abstenerse de consumirbebidas alcohólicas o utilizar sustancias estupefacientes.

3. ${ }^{\circ}$ ) Adoptar en el plazo de quince días, oficio, arte, industria o profesión, y acreditar ese extremo ante el Departamento de Reinserción Social del Liberado.

\section{$4 .^{\circ}$ ) No cometer nuevos delitos.}

5. $\left.{ }^{\circ}\right)$ Someterse al cuidado del Departamento de Reinserción Social del Liberado - Ministerio de Seguridad, Gobierno de la Provincia-, organismo que deberá informar a este juzgado cualquier incumplimiento en que incurriese el interno respecto de sus obligaciones de comparendo y velar por la inclusión sociolaboral del mismo. 
Todas estas condiciones regirán hasta el vencimiento de la pena privativa de la libertad impuesta (04/08/2013), so pena de serle revocado el beneficio.

II. REGÍSTRESE, notifíquese, comuníquese a la administración con copia del presente.

\section{Caso B}

RESOLUCIÓN INTERLOCUTORIA N. ${ }^{\circ}$ XXX

XXX, Veinticinco (25) de JUNIO de dos mil trece.

\section{VISTOS}

Estos autos caratulados «XXX S/ EJECUCIÓN DE PENA PRIVATIVA DE LIBERTAD», Expediente N. ${ }^{\circ}$ XXX, del Registro de este Juzgado de Ejecución Penal de 1. ${ }^{a}$ nominación.

\section{CONSIDERANDO}

I. Que a fs. 281 el interno XXXX, Legajo Penitenciario N. ${ }^{\circ} \mathrm{XXX}$, argentino, soltero, nacido en XXX el diecisiete de septiembre de mil novecientos ochenta y cinco, hijo de XXX y de XXX, DNI N. ${ }^{\circ}$ XXX, Prontuarios N. ${ }^{\circ}$ XXX y XXX, ambos sección AG, solicita se le conceda la libertad condicional.

II. Que a fs. 291 se dispone vista de lo peticionado al Sr. Fiscal Correccional de I Turno y al Defensor de XXX.

A fs. 292/293, el Sr. Representante del Ministerio Público Fiscal evacúa el traslado conferido. El Dr. XXX, luego de analizar las diversas exigencias que la ley establece a los efectos de la concesión del instituto que peticiona, concluye: «Este Ministerio es de la opinión que, por el momento, NO EXISTIRÍA UN PRONÓSTICO FAVORABLE del cual pueda inferirse que el interno XXX haya adquirido, durante su encierro, la capacidad de comprender y respetar la ley, procurando adecuarse a la reinserción social.

En consecuencia, se considera que aún NO ESTARÍAN DADAS LAS CONDICIONES (por incumplimiento de los requisitos... subjetivos), para que el nombrado interno pueda acceder al beneficio de la "libertad condicional"»».

A su turno, el defensor del interno, Sr. Asesor Letrado de Penados, Dr. XXX, a fs. 294/296, se expide en sentido negativo al Sr. Fiscal relativizando los argumentos denegatorios y evaluando como procedente el beneficio solicitado.

III. Que considero que la libertad condicional que se peticiona no debe ser concedida.

En efecto:

1. $\left.{ }^{\circ}\right)$ La libertad condicional permite la externación anticipada de un condenado a pena privativa de la libertad que se está ejecutando, en la medida en que haya cumplido con los presupuestos que establece la ley y bajo las condiciones que también allí se consignan.

Entre los presupuestos que deben verificarse se encuentran (texto según la Ley 25.892 - vigente al momento del hecho motivo de juzgamiento): a) la solicitud del condenado; b) que se encuentre cumpliendo una pena privativa de libertad impuesta de modo efectivo por condena firme y en carácter de sanción principal; c) que haya cumplido el mínimo de encierro carcelario que establece el Código Penal; d) que haya observado regularmente los reglamentos carcelarios; e) informes del director del establecimiento y de peritos que pronostiquen en forma individualizada y favorable su reinserción social; f) que la ponderación ínsita en la calificación de concepto lo haga merecedor de la aplicación de este instituto y g) que no se encuentre el interno en ninguno de los obstáculos impeditivos que surgen de los artículos $14 .^{\circ} \mathrm{y}$ 17. ${ }^{\circ}$ del Código Penal.

2. $\left.{ }^{\circ}\right)$ Que el análisis del legajo me permite afirmar que, en el presente caso, la improcedencia de la libertad condicional debe fundarse en el defecto de la exigencia relacionada con la observancia regular de los reglamentos carcelarios y el déficit conceptual. Veamos:

A) El penado XXX fue condenado por la Cámara en lo Criminal de $11 .{ }^{\mathrm{a}}$ nominación a la pena de cinco años de prisión, unificando condena con anterior oportunamente dictada por la Excma. Cámara Octava en lo Criminal, en la pena única de siete años y seis meses de prisión. El interno fue detenido en las siguientes oportunidades: a) del 19/09/2006 al $11 / 10 / 2006$ y b) $02 / 07 / 2008$, sin recuperar la libertad hasta el día de la fecha (fs. 12 vuelta), fijándose como fecha de cumplimiento total el 10/12/2015. 
B) El informe del área seguridad, glosado a fs. 286/289, da cuenta de su evolución de conducta en los siguientes términos:

a) $01 / 10 / 08$, Muy Buena 8

b) $08 / 01 / 09$, Buena 6

c) 06/04/09, Pésima 0

d) 07/07/09, Pésima 0

e) 01/10/09, Pésima 0

f) 04/01/10, Pésima 0

g) 04/04/10, Pésima 0

h) 01/07/10, Pésima 0

i) 01/10/10, Pésima 0

j) 11/01/11, Pésima 0

k) 01/04/11, Pésima 0

1) $10 / 07 / 11$, Pésima 0

Ll) 01/10/11, Pésima 0

m) $08 / 01 / 12$, Mala 01

n) $15 / 04 / 12$, Pésima 0

o) 01/07/12, Pésima 0

p) 10/10/12, Pésima 0

q) 01/01/13, Pésima 0 y

r) 01/04/13, Pésima 0

Asimismo, se registraron 68 procedimientos sancionatorios computables (no valoro 3 procedimientos en los que resultó eximido) seguidos en su contra; las que epilogaron en la constatación de 68 infracciones: 8 graves, 4 leves y las restantes de entidad media.

C) En orden a la observancia regular de los reglamentos carcelarios, tengo comprometida opinión en el sentido que tal exigencia «debe entenderse en función de la valoración de la conducta. Ello por cuanto, solo de esa manera, se puede asegurar que dicha apreciación tendrá un carácter netamente objetivo, en el sentido que parte del comportamiento exterior del penado» (cfr. Cesano, 2002, pp. 86-87). Sobre esta base interpreto que «la observancia de los reglamentos carcelarios que menta el artículo $13 .^{\circ}$ del código alude al respeto, por parte del interno, de las normas «que rigen el orden, la disciplina y la convivencia dentro del establecimiento (artículo $100{ }^{\circ}$ de la ley 24.660 - artículo $53 .^{\circ}$ del anexo IV del decreto 1293/2000), conceptos que no pueden ser definidos positivamente sino en función de su faz negativa; esto es: la imposición de sanciones disciplinarias (...) por inobservancia de aquellas normas reglamentarias» (Cesano, op. cit., pp. 89-90).

Sobre tal base hermenéutica y teniendo en cuenta el informe del área de seguridad que se glosara supra, resulta evidente que respecto del penado no puede considerarse satisfecha esta exigencia. En efecto, en el periodo que lleva institucionalizado — vale decir, en poco menos de cinco años-, XXX, como ya lo señalé, ha sido objeto de sesenta y ocho procedimientos disciplinarios los que concluyeron con la acreditación de 8 faltas graves, 4 leves y las restantes de carácter medio. Esta circunstancia, evaluada tanto desde un punto de vista cuantitativo (número de infracciones verificadas) como cualitativo (gravedad de las mismas) - criterio de ponderación que realiza nuestro Excelentísimo Tribunal Superior, en jurisprudencia reiterada (cfr., entre otros, "XXXX, xxx - Recurso de casación», Sentencia N. ${ }^{\circ} \mathrm{XXX} / 94,2000$, p. 325), me permite sostener que el interno no ha alcanzado una estabilización de su comportamiento. Es que, si la aceptación de las normas disciplinarias resulta indicativa de un cambio de actitud con relación a los límites que exige la convivencia, el nutrido elenco de sanciones verificadas durante su institucionalización y la entidad de las mismas hacen que, en el presente caso, no pueda darse por cumplimentado el requisito que se analiza.

Es más: el repaso de las calificaciones demuestra además una ponderación general negativa que, en los últimos tiempos, las evaluaciones en vez de mejorar tienden, por el contrario, a un empeoramiento tal que las ubican en el umbral más bajo posible de los guarismos establecidos por la reglamentación vigente. En concordancia con lo que vengo sosteniendo, el área de seguridad concluye: «Interno de un permanente accionar trasgresor que se manifiesta abiertamente en contra del régimen disciplinario, así como también de toda normativa que regule su convivencia institucional, atribuyendo tal comportamiento 
a que, debido a las consecuencias lógicas de su historia de conducta reacia durante su institucionalización siendo la misma, lamentablemente, el aspecto más constante por el que se lo puede conceptuar, a la fecha no puede aspirar a ningún beneficio en la duración de su pena, dejando entrever su desinterés en aplicarse a programas de tratamiento que signifiquen un avance en su proceso de recuperación» (fs. 288).

Asimismo, el informe del área de psicología tampoco se muestra auspicioso, en cuanto de él se desprende que: «En función de la aproximación de la posibilidad de egresar anticipadamente, se realiza el presente informe, destacándose que es una reconstrucción de lo actuado por profesionales anteriores, ya que hace más de un año es voluntad de XXX no asistir a psicología, por lo cual no hay entrevistas recientes, ni se puede evaluar su estado anímico actual. Durante su etapa como procesado, se aprecia que el contacto con Psicología fue a través de audiencias y de convocatorias del área en función de la problemática autoagresiva observada (adicción marcada e ideas de muerte), "abordando principalmente cuestiones relacionadas en el tránsito institucional, referidas al grupo familiar y al consumo de sustancias tóxicas... en los encuentros mantenidos se presenta con un discurso verborrágico y una actitud demandante. Se observa precariedad simbólica y escasa tolerancia a la frustración... tensión subjetiva $\mathrm{y}$ un posicionamiento rígido... manifestando explícitamente su necesidad de recibir un tratamiento a los fines de abandonar el consumo..., motivo por el cual es derivado en ese momento al Centro de Atención de Adicciones (marzo/10) (...); respecto de la variable delictiva, en las oportunidades en que fue abordado el hecho por el cual cumple condena, se apreció un reconocimiento del mismo vinculándolo a su conducta adictiva» (fs. 284 vuelta y 285).

Destaco, asimismo, que el registro conceptual de XXX es Pésimo. Este dato está señalando una deficitaria prognosis de reinserción, por cuanto no refleja una evolución personal positiva del penado. En efecto, sin desconocer que ha tenido contactos con el área educativa, la evaluación realizada por laborterapia también se muestra poco alentadora. En efecto, el informe criminológico de fs. 284 sintetiza este aspecto expresando: «Interno que fue incorporado al programa de capacitación laboral en este establecimiento (EP N. ${ }^{\circ} 2$ ) el día 1/9/2009 para desempeñarse como operario en el taller de herrería, División Industria, desempeñándose hasta el 17/5/2011, fecha en la que fue dado de baja por falta de interés y compromiso. A la fecha no se registran audiencias manifestando interés en ser incorporado en alguna actividad laboral».

$3^{\circ}$ ) Por último, y teniendo en cuenta lo apuntado por el equipo psicológico tratante del interno XXX, se recomienda continuar con el ofrecimiento de tratamiento psicológico «intramuros» por un período no menor a 6 meses, plazo en el cual se deberá profundizar lo atinente al control de los mecanismos agresivoimpulsivos y su problemática adictiva.

En razón de todo lo expuesto, de conformidad a lo dictaminado por el Sr. Fiscal Correccional y atendido el informe de la Dirección del Establecimiento en donde se encuentra alojado el penado, SE RESUELVE:

I. NO HACER LUGAR al pedido de libertad condicional formulado por el interno XXX, Legajo N. ${ }^{\circ}$ XXX (artículo 13. ${ }^{\circ}$, a contrario sensu, CP).

II. DISPONER que, a través del área psicología, se continúe ofreciendo un tratamiento psicoterapéutico, a favor del interno XXX, Legajo N. ${ }^{\circ}$ XXX por un plazo no menor a 6 meses, con informes mensuales de evolución a este Juzgado de Ejecución Penal, y con el propósito de abordar aspectos vinculados con el control de los mecanismos impulsivoagresivos y de su problemática adictiva.

III. DISPONER que, a través de la Dirección del establecimiento, proceda a convocarse al penado XXX y ofrecerle su inclusión en programas laborales, rentados o voluntarios.

IV. PROTOCOLÍCESE, notifíquese y comuníquese.

\section{ALGUNAS ACLARACIONES CONCEPTUALES}

Como puede apreciarse, este tipo de resoluciones interlocutorias que otorgan $o$ rechazan la libertad condicional o asistida tienen una estructura normalizada. Se presenta el nombre del condenado y su respectiva 
filiación. Luego se da la palabra al fiscal y al defensor en este orden. Finalmente, en esta fase introductoria, el juez de ejecución, y si no lo hubiera, el juez competente de la jurisdicción correspondiente, adelanta su posición.

En una segunda parte, aparecen los fundamentos del juez para otorgarla o denegarla; finalmente, se compone la instancia destinada a la etapa resolutoria.

Como durante la lectura aparecen algunos términos que no pueden darse por sentados, ya que son propios del lenguaje del derecho, intentaremos hacer la lectura lo más fluida posible y aclarar algunos conceptos importantes, dado que este texto será leído eventualmente por personas de diferentes profesiones y especialidades.

\section{DERECHO PENAL DE AUTOR Y DERECHO PENAL DE ACTO}

El derecho penal de autor pretende juzgar a la persona por lo que es y no por el delito cometido (Zaffaroni, 1992).

En cuanto a los orígenes de esta concepción, tanto Lombroso como sus precursores y seguidores encontraron precisamente lo que buscaban: el delincuente como un fenómeno aislado, objeto de consideración científica e inmóvil bajo la lente del microscopio de los fieles a la ley. El modelo del autor asume que las características personales del inculpado son el factor clave que se debe considerar para justificar la imposición de la pena. Al sujeto activo del delito, que en esta teoría suele ser llamado «delincuente», se le adscribe la categoría de persona desviada, enferma, desadaptada, ignorante, entre otros calificativos que no han sido borrados del todo en el imaginario social actual. Esta categorización cumple la función de impactar en el aumento de la pena, permitiendo castigar por las cualidades morales, personalidad o comportamiento precedente frente a la sociedad, estableciéndose una prognosis por lo general negativa (peligrosidad) (Hassemer, 1984).

Por su parte y al contrario, el derecho penal del acto no justifica la imposición de la pena en una idea rehabilitadora, ni busca el arrepentimiento del infractor; lo asume como un sujeto de derechos $y$, en esa medida, presupone que puede y debe hacerse responsable por sus actos. Por ello, la forma en que el individuo lidia con su responsabilidad penal en términos personales, queda fuera del ámbito sancionador del Estado. Prohíbe condenar a la persona y a sus características individuales, sociales, familiares, etc. En el derecho penal de acto solo se juzga la acción cometida que viole la ley.

\section{REINCIDENCIA}

«Habrá reincidencia siempre que quien hubiera cumplido, total o parcialmente, pena privativa de libertad impuesta por un tribunal del país, cometiere un nuevo delito punible también con esa clase de pena.

La condena sufrida en el extranjero se tendrá en cuenta para la reincidencia si ha sido pronunciada por razón de un delito que pueda, según la ley argentina, dar lugar a extradición.

No dará lugar a reincidencia la pena cumplida por delitos políticos, los previstos exclusivamente en el Código de Justicia Militar, los amnistiados o los cometidos por menores de dieciocho años de edad. La pena sufrida no se tendrá en cuenta a los efectos de la reincidencia cuando, desde su cumplimiento, hubiera transcurrido un término igual a aquel por la que fuera impuesta, que nunca excederá de diez ni será inferior a cinco años» (Código Penal de la Nación Argentina, 1984).

\section{PRISIONIZACIÓN}

Es el proceso de adopción de los usos, costumbres, valores, normas y cultura general de la prisión, es decir, la asimilación o interiorización de la vida carcelaria. Comienza con el ingreso a prisión, asumiendo el rol que les corresponderá según las jerarquías establecidas por el propio grupo de presos (tipo de delito cometido, antecedentes del afuera). Por ejemplo, si es reincidente, le corresponderá una mayor categoría en la pirámide de estatutos como el haber dado muerte a un policía; estos se reflejan en la forma que adquieren los tatuajes carcelarios (en la jerga carcelaria se los llama «tumberos»). Se desarrollan nuevas formas de comer, vestir, dormir, trabajar, comunicarse, consumo de drogas, actividades homosexuales, desconfianza, incluso odiar a los funcionarios y aceptar las costumbres y valores de la comunidad de presos. Asimismo, y de acuerdo con el discurso carcelario, «dormir con un ojo abierto», es decir, estar siempre en 
un estado de alerta sea por robos, peleas u otras inconductas típicamente carcelarias.

La prisión tiene, al menos, dos reglamentos de conducta: uno formal, el de la administración carcelaria que debiera fundamentarse en la Ley de Ejecución Penal, y otro informal, de parte de los detenidos sobre los que se organiza la convivencia. La prisionalización, entendida como institucionalización, supone la expresión de comportamientos concretos que superan la individualidad al hacer depositarios o responsables de estos el ambiente al que se pertenece. Dentro de los roles desarrollados durante la estancia en prisión se encuentran los denominados preceptos carcelarios, como un elemento de primer orden, sistemas de normas tácitas, no escritas ni refrendadas formalmente, que condicionan el ambiente de esta institución. La aceptación de las claves carcelarias depende del grado de criminalización del interno expuesto a este. Una extensa y densa carrera delictiva lo hace especialmente proclive a la asunción de los valores y de las conductas negativas asociadas a lo que se muestra en las normas de la prisión (Hood y Sparks, 2006; Wheeler, 2007).

Se trata de una sobreadaptación carcelaria que afecta la identidad de las personas con distintos grados de intensidad. Esto pondrá serias trabas a la hora de volver a la sociedad libre, ya que se descuenta que, una vez finalizado el periodo de encierro, la persona podrá comportarse, aun mejor que antes, de acuerdo con las reglas de la vida social. Como cualquier otro individuo que no ha cometido un delito y no ha sufrido el proceso penal/carcelario, deberá conducirse con las habilidades sociales, relacionales, laborales y demás requisitos obviando las consecuencias que acarrea en una identidad deteriorada o frágil, que la estadía carcelaria ha enfatizado y que suele venir de su propio estilo de vida.

\section{CONCEPTO}

En el régimen penitenciario se evalúa la presencia o ausencia de evolución en el tratamiento: asistencia a la escuela, talleres laborales y cualquier otra actividad que se ofrezca para mejorar las habilidades sociales y competencia laboral, entre otras finalidades, con el comportamiento que tiene durante las visitas, sus relaciones con el servicio penitenciario y con los restantes detenidos.
Además, se incorpora el estímulo y voluntad de pedir ayuda psicológica que tiene el condenado en el caso de drogadicciones, alcoholismo y demás alteraciones de la conducta.

\section{CONDUCTA}

En este caso, se evalúa la observancia regular de los reglamentos carcelarios. Las infracciones constituyen el quiebre o la falta de respeto que tienen por consecuencia directa las sanciones que, en conjunto, desmejoran la evaluación final para el otorgamiento de la libertad condicional.

\section{CONSIDERACIONES GENERALES SOBRE LA LIBERTAD CONDICIONAL: INCONGRUENCIAS PROPIAS DEL CONCEPTO DE "LIBERTAD CONDICIONAL" Y CONFLICTOS EXISTENTES ENTRE LA LETRA DE LA LEY Y LAS CONDICIONES CONCRETAS DE SU APLICACIÓN}

Respecto del primer punto, son los propios analistas doctrinarios y jurisprudenciales quienes se refieren a la falta de «exactitud» o de un criterio de exclusión - es decir, con límites precisos y no ambiguos- del significado rector y unificado que permita aplicarla sin excesivo margen de interpretación que deja a quien tiene que decidir entre otorgarla o no. Indican que el trasfondo sigue siendo punitivo, ya que forma parte inexcusable del cumplimiento de una pena de privación de la libertad ambulatoria.

Cesano (2004), entre otros, sostiene primero que la libertad condicional constituye la última etapa del régimen penitenciario, que se caracteriza por la «progresividad» y se concreta la libertad. Postula que la tesis sobre la que se suspende la ejecución confunde "encierro» con ejecución de la pena privativa de libertad, quedando sometido a la observancia de ciertas condiciones. Intenta hacer una diferencia estricta entre «estar en libertad»y «estar en libertad condicional», en esta última se permanece cumpliendo la condena bajo ciertos requisitos fuera de la cárcel, pero no en libertad. Este comentario comienza a indicar que hay zonas oscuras, que permite interpretaciones exageradas o desviadas de la ley en cuestión o, al menos, como está redactada. 
El mismo autor sostiene una postura distinta en el 2008, considerando ahora que la libertad condicional no es parte del régimen de progresividad sino que es un instituto autónomo, con propia identidad y distintivo, de modo que su naturaleza jurídica es diferente de quienes lo consideran como la última etapa de las fases de progresividad.

Otros autores indican que el tratamiento penitenciario tiene un factor no despreciable coercitivo de la limitación de la libertad ambulatoria, pero que a la vez existe un régimen de progresividad que le permite alguna flexibilidad, después de cierto tiempo calculado de acuerdo con la longitud de la pena impuesta. Muy conocedores de los derechos que los asisten algunos detenidos pueden armar una «máscara» de buena conducta para obtener un puntaje aceptable. A esto último se llama «hacer conducta» en el lenguaje carcelario. En nuestra experiencia, hemos escuchado más de una vez la expresión bíblica «la piel de cordero» como pauta de comportamiento dentro de la cárcel, siendo presos «modelo» para el ideario penitenciario pero, en ciertos casos y una vez en libertad, se rompe esa coraza autoimpuesta para volver al camino del delito ${ }^{11}$ (Harding, 2003; Kalinsky, 1997).

Entre la letra de la ley y su aplicación y efectos en la realidad concreta hay una fisura cuyos principales problemas son la falta de supervisión adecuada (jurisdiccional) así como la ideología que subyace a este instituto jurídico; ambas se notan cuando se ponen en práctica en cada caso.

La libertad condicional tendría que ser considerada bajo términos acorde a las necesidades que cada persona enfrenta, dado que los contextos del delito y las formas de encarcelamiento tienen matices distintivos (contexto de la ofensa, familiar, comunitario, institucional, biográfico, rutas de vida, entre otros factores) (Comfort, 2009). Se trata de un colectivo de problemas, puntos de inflexión y zonas críticas que conforman un mismo nudo de faltas, improvisaciones y desapoyos que la literatura científica suele identificarlos

11 En uno de los casos analizados, se le preguntó al reo que estaba cerca de recibir la libertad condicional si estaba convencido de abandonar el delito como plan de vida. La respuesta fue lo más honesta posible según su propia perspectiva, diciéndonos que recién tanto él como nosotros la íbamos a tener cuando respirara la primera gota de aire libre (Notas de campo, febrero 2014). $\mathrm{y}$ analizarlos por separado $\mathrm{y}$ en términos generales.

\section{VIDA CARCELARIA Y LIBERTAD CONDICIONAL}

En el ambiente carcelario no hay tratamientos con continuidad para el uso indebido de alcohol y drogas (Hammet, Roberts y Kennedy, 2001; Richie 2001; Surratt, 2003). Al contrario, las administraciones penitenciarias no parecen registrar que estas sustancias son de uso cotidiano, circulan «libremente» en los pasillos y celdas carcelarias (mercado negro donde está implicada la propia agencia penitenciaria ${ }^{12}$ ), a pesar del superficial excesivo celo puesto en inspecciones de familiares $u$ otros visitantes al momento de la entrada los días de visita y en las dos o tres requisas diarias en las celdas.

Como se dijo, la condición para acceder a este derecho está dada por tres ítems: que en la cárcel se hayan ejecutado las dos terceras partes de la condena, que los informes correccionales sean favorables y que sea un pedido personal del detenido, no intermediado.

El primero de los requisitos para obtener la libertad condicional se consuma con el paso del tiempo, mientras que el segundo responde a la conducta penitenciaria y al concepto de la persona que deberá ser evaluada por las juntas correccionales que tengan jurisdicción. Estas dictaminan si se está en condiciones de retornar a la vida libre en forma condicional (Birbeck, 2003). En este aspecto, el problema reside en hacer una homologación entre lo que una persona puede hacer, pensar, sentir y convencerse de la bondad de ciertos parámetros de comportamiento en un establecimiento carcelario definido por el hermetismo, la inexpresividad emocional y la violencia institucional, interpersonal y comunicativa, así como las pautas de actuación en la sociedad libre.

Ya se ha enfatizado en que no se puede «entrenar» para la vida libre, en cuanto a habilidades y capacidades sociales en un establecimiento cerrado (Añez Castillo, Han Chen Morales Manssur y Párraga Meléndez, 2008; Birbeck, 2003; Crewe, Warr, Bennett y Smith, 2013).

12 Comunicación personal proveniente del propio servicio penitenciario del lugar del trabajo de campo, bajo reserva de identificación. Mayo de 2013. 
Los resultados de los informes a los que hemos accedido hacen que insistamos en que se dé prioridad al cumplimiento de las reglas carcelarias, administrativas y burocráticas (control disciplinario) ${ }^{13}$. Recién, en segundo término, a la participación en las escasas actividades que ofrecen en los rubros laboral y educativo. Otras variables no median en forma estricta en la práctica, tal como la necesidad de establecer y mantener vínculos sociales externos durante la ejecución de la pena a fin de satisfacer los requisitos de tener vivienda, trabajo y demás pautas que fija la ley antes de salir de la cárcel; de igual manera, el influir y compensar las carencias afectivas previas, a las que se suman las generadas por las estadías carcelarias. En este sentido, las visitas familiares pueden ser beneficiosas, siempre y cuando el delito no haya sido contra algún miembro de la familia, como pueden ser los casos de violación y homicidio. La preparación para la salida en libertad debería iniciarse desde el primer tiempo en la cárcel, pero por sus índoles contrapuestas es una tarea irrealizable. La insidiosa presencia de la hermeticidad de la cárcel, de sus pautas vinculares violentas, de su simbolismo como institución denigrante y estigmatizadora, desfigura la capacidad de pensar, planear y actuar en consecuencia para cumplir con los requisitos exigidos que permitan hacer uso del derecho de la libertad condicional.

\section{PROGRAMAS DE REHABILITACIÓN Y VUELTA A LA LIBERTAD}

La idea de programas de «rehabilitación» encierra cuestiones que ya no pueden sostenerse: Tratan de imponer un cambio de actitud hacia la vida y los semejantes que se dirige al núcleo de la conciencia moral de cada persona, invadiendo esferas de la vida privada, en primer término, y a elecciones particulares o modos de estar en el mundo que algunas personas querrán examinar críticamente, pero otras no (Garland, 2005; Rodríguez, 2006). Si bien algunos jueces de ejecución insisten en un tratamiento penitenciario «mínimo» para advertir sobre este peligro, durante la realización concreta se lo pasa por

13 Se toma en cuenta el comportamiento durante "la visita", ya que quienes van suelen ser objeto de estrictas requisas que incluyen en forma rutinaria las vejaciones y humillaciones de familiares y amigos, por lo que el detenido suele iniciar un comportamiento de protesta. alto, ignorándose el posible irrespeto por las creencias profundas de las personas en un intento por «eliminar» los rasgos delictivos, por lo que este tratamiento se acerca a un derecho penal de autor otra vez.

Los programas de capacitación ofrecidos en las unidades penitenciarias —ya sea que se consideren o no de rehabilitación, según quién los valore - son escasos, incompletos o desactualizados, ya sea en los niveles de escolarización primario y secundario o en los talleres. Los maestros, profesores o talleristas que asisten tienen dificultades para la entrada al establecimiento, con lo que el tiempo destinado a las clases se reduce en forma considerable. Las técnicas pedagógicas no están adaptadas a la situación de estrés de los alumnos y tampoco se trabaja el sentido de enfatizar que estudiar o adquirir algún oficio pueda considerarse una inversión de tiempo y esfuerzo que valdrá la pena una vez en libertad. La asistencia es optativa, aunque la inasistencia a estos cursos «rebaja el puntaje» correccional, de modo que depende de la actitud proactiva del detenido el presentarse y darle continuidad al curso elegido, en ocasiones escogido solo para «matar el tiempo muerto» de la cárcel (Messuti, 2001).

Los cursos que se ofrecen tienen una marcada tendencia de género (Bosworth y Carrabine, 2001; O`Brien, 2001). Para los hombres se da capacitaciones en carpintería, herrería, trabajos en mimbre o madera, y para las mujeres se ofrece cocina, repostería, corte y confección, entre los más generalizados. Hay mínimas posibilidades para cursar los estudios secundarios; entonces, se «repasan» los de nivel primario, incluso varias veces, que se vuelve a iniciar cada vez que soportan un traslado no voluntario de unidad de detención.

Lo que importa aquí es enfatizar que nadie se encarga de motivar a la gente a que concurra por razones genuinas, tales como estar entrenado para encontrar trabajo, tener herramientas para sostener económicamente a la familia, mejorar la autoimagen, fomentar las capacidades personales, encontrar algún grado de satisfacción consigo mismo, mejorar la percepción del grupo familiar o de pertenencia de la persona, y volver a ocupar el rol familiar y social que le corresponde (ser padre, ser madre, ser hijo). No obstante, motiva a estar ubicado en otro lugar de mejor calidad respecto del que se salió para ir a la cárcel. 
La pena de privación de la libertad fue y sigue siendo punitiva (Foucault, 1990). Es la razón "privilegiada» que encontramos para que existan y se mantenga tal cantidad de impedimentos, dificultades y desaciertos en la implementación de puntos de apoyo en los que detenidos puedan acudir en forma voluntaria y electiva de acuerdo con una evaluación compartida (expertos y los propios interesados) de sus necesidades e inclinaciones.

Las personas que han pasado tiempo encerrados enfrentan dificultades cuando están, por fin, en la sociedad libre. Esta «condicionalidad» se vuelve el principal escollo en el campo de sus expectativas. Se hacen esfuerzos pero se fracasa una y otra vez. Ya no se trata solo del problema de la «institucionalización», de quien se acostumbra a un ambiente enredando su propia identidad con el juego institucional y sacrificando su autonomía en un cálculo de beneficios-pérdidas de la cárcel como un lugar de asistencia social. En estos tiempos, esta se ha convertido en una agencia del Estado destinada a la acción social (Colmenarez Isturiz, 2005; Kalinsky y Cañete, 2010; Robinson, 2008; Wacquant, 2000).

Nadie se cerciora de que se hayan entendido a cabalidad los términos de la liberación condicional sin haber tampoco, en nuestro caso de estudio, una supervisión sensible que a la vez se concrete con un detenido establecimiento de límites. En términos reales, tal «acuerdo» de condicionalidad de la libertad se lleva a cabo en forma unilateral. El detenido difícilmente tendrá alguna voz en la decisión del consejo correccional; de hecho no se lo entrevista salvo por razones excepcionales. Dicho fallo lo establece el juez de ejecución o quien actúa en términos jurisdiccionales, basado en el informe del consejo correccional que se nutre, a su tiempo, en los que han redactado los distintos sectores pertinentes (laboral, educacional, de seguridad y criminológico).

Las personas que acceden a la libertad condicional se encuentran en una situación particular: siendo adultas, han perdido buena parte de las habilidades sociales, por su desuso y porque se topan con un mundo desconocido, ya que el acelerado desarrollo tecnológico y el continuo cambio del orden regional y mundial (del que tienen una referencia incompleta) han modificado las pautas de relacionamiento con casi todo, de tal forma que son extraños y están fuera de lugar.

\section{EL CONTEXTO SOCIO-POLÍTICO DE LA LIBERTAD CONDICIONAL}

No es difícil prever, entonces, las condiciones que atrapan la libertad, ya que los requisitos, de difícil alcance, facilitan la suspensión de la libertad condicional (Scott, 2004).

Si tienen un lugar para vivir, están adeudando impuestos, no tienen luz por falta de pagos o se ha deteriorado con el simple paso del tiempo sin que existan recursos para mantenerlo. Las familias tienen los mismos problemas que antes, incluso empeorados, porque los hijos han crecido sin que esas faltas materiales, emocionales, educativas, laborales y afectivas fueran cubiertas ni atendidas. Además, deben seguir lidiando con sus propias carencias que no fueron paliadas durante su estancia carcelaria. Por ejemplo, el retorno al menudeo de drogas se presenta como una solución «razonable» a corto plazo, siendo una forma social adaptativa en contextos inestables (Scott, 2004). A quien ha estado en la cárcel le sobreviene un etiquetamiento social por el que se convierte de por vida en alguien "peligroso», «contagioso» o "sucio», entre otros calificativos de orden despreciativo (Leverentz, 2001; Maruna, 2001; Scott, 2004).

Cualquier problema que surja se le endilgará en forma inmediata, indistintamente del delito por el que haya estado sometido a procesos penales y cumplido con la correspondiente reparación (condena - privación legítima de la libertad). Así, será el primero en ser despedido, en tener empleo sin los derechos que marca la ley laboral, en ser sometido a servidumbre a sabiendas de que no puede conseguir nada mejor, en ser denunciado. Siempre será el primer sospechoso.

Elvecindariosuelerechazarlos porhaberestado presos. Este comportamiento puede deberse a que la comunidad tiene la comprobación de los repetidos encarcelamientos de algunos de sus miembros, por lo que temen la criminalización de todo el cuerpo social y que el barrio entero se perjudique (Leverentz, 2001). Los excarcelados por los distintos tipos de institutos que otorga la ley de ejecución penal deben enfrentarse a condiciones sociales e institucionales empeoradas de cuando se fueron, debido no solo a las consecuencias económicas y emocionales de su ausencia, sino también a las dificultades de quienes 
han quedado afuera para tomar en todo o en parte su rol - quién trabajó, quién cuidó de la prole, cómo se repartieron las funciones parentales en el conjunto de personas que están vinculadas emocionalmente con los niños (los más vulnerables y dañados por esta situación)-.

En nuestra experiencia, algunos de los barrios analizados se asientan en tierras fiscales o son producto de la privatización de empresas públicas; otros son cooptados por supuestos beneficios de actividades ilícitas (distribución, tráfico y comercialización de drogas), que a la vez son objeto de luchas entre partidos políticos, que sufren los vaivenes sobre todo de las épocas electorales («tomas», «okupas» en la jerga local). Es entonces el propio Estado quien remata la ilegalidad de tomar tierras que no compran, sobre las que no se paga impuestos, que no tienen mensura ni título de propiedad mediante su urbanización (luz, gas, cloacas, por provisorios que sean estos servicios). Esto se da sin exigir pago, ya que son personas titulares de planes sociales que, si bien importa una contrapartida de trabajo o capacitación, raramente se cumple. Nada más tienen que afiliarse a tal o cual partido político y solo tienen como carga laboral asistir a mítines, concentraciones o protestas.

Los proyectos que idean e intentan las asociaciones vecinales, clubes u otras formas de organización intermedia no son del todo viables porque quedan incrustados en la puja política que impide la coordinación sistemática de voluntades para conseguir un fin acordado entre los integrantes de estos barrios. La cárcel es una forma que adquiere la constante confinación de los pobres en guetos. Pareciera preferible conservar la idea de que el delito es una acción individual (antes que vincular o contextualizar), de alguien, que plenamente informado sobre las consecuencias que puede acarrearle, elige una forma «fácil» para «pasar la vida». Es, entonces, su «incumplimiento» un tema de libre albedrío en cuanto a respetar o no este orden de la vida. Tales convicciones ideológicas respecto del delito le subyace la certeza de que hay una sola visión correcta del «bien» y el «mal», y de cómo la sociedad debe reaccionar, renunciando a asumir la parte que le compete en la construcción, sostenimiento y aumento de los diferentes ámbitos de criminalidad (Hammett, Roberts
\& Keneddy, 2001; Maruna, 2001; Marchetti, 2002; Silva Sánchez, 2002).

Hasta que no sean ciudadanos competentes, viven en libertad a «condición» de que adecúen sus comportamientos a los estándares admitidos y que, en principio, estarían cumpliendo el resto de las personas. Pero, una vez que han sido estigmatizados como «criminales», «malvivientes» o «exconvictos» (que los definen como personas inferiores), la ciudadanía condicional quedará perpetuada y seguirá su ruta hacia las generaciones posteriores.

\section{ANÁLISIS DE LAS RESOLUCIONES INTERLOCUTORIAS}

Es en este contexto amplio donde se pueden analizar en determinados aspectos las resoluciones interlocutorias que se incluyen en este artículo.

\section{CASO A}

En los considerandos aparece una persona que tuvo una vida inestable y poco apegada a las normas sociales, aun antes de su periodo de encarcelamiento. En su encierro tuvo procesos disciplinarios: uno de ellos fue no regresar luego de una salida transitoria, lo que constituye una falta de orden «medio» - a saber «no respetar las normas establecidas durante el goce de salidas transitorias o en semilibertad»- (Ley de Ejecución Penal 24.660/96).

Dentro de la cárcel puede haber acatado todas las normas administrativas sin problemas, pero en el afuera mantiene un comportamiento semejante al que vivió antes de ser detenido, ya que no retorna de su salida. Expresa nuevamente su desapego a una norma con la que estuvo, en principio, de acuerdo. Esto no es muestra de que su «mala conducta» se reproduzca necesariamente en la cárcel, pero sí muestra que el «hacer conducta» en la cárcel puede convertirse en una impostura para obtener el puntaje necesario a la hora de solicitar el derecho de las distintas libertades que otorga la ley de ejecución penal. Muestra, asimismo, una hipótesis más general que ya ha sido anticipada: No se puede generar en forma genuina, crítica y reflexiva una conducta de respeto a las normas en un ambiente de encierro, violento, de órdenes muchas veces arbitrarias, donde los castigos no constan en 
los contenidos específicos de sus expedientes (aislamiento, celdas especiales, y abusos) y a los que, con toda razón, se les teme. ${ }^{14}$

Ya afuera, especialmente en las libertades transitorias, sea para trabajar, estar con su familia por motivos de visita o por una salida de fin de semana, debe volver a la cárcel a una hora establecida.

Hemos visto la dramática resistencia que muestran tanto hombres como mujeres para el regreso a la cárcel. En el caso de una joven condenada por robo en calidad de cómplice a cinco años de prisión de cumplimiento efectivo, era el propio padre quien debía no solo acompañarla sino entrar él mismo a la sala donde se hacía la requisa y ver que su hija pase por las rejas que se cerraban detrás, hecha siempre un mar de lágrimas. Todas las veces se dio el mismo escenario. Hay un conjunto complejo de factores que, por un lado, pueden impedir el regreso a la cárcel y, por ende, resultar en el incumplimiento de lo prometido; por el otro lado, volvemos a enfatizar que el dentro y fuera de la cárcel son cualitativamente diferentes, de modo que no se puede hacer una comparación, en especial de la estabilización de la conducta entre los dos ámbitos. El significado de uno y de otro no permite generar algún criterio, ya sea de «medición» o de «cualificación».

Dentro de la cárcel, hay una dimensión normativo-administrativa establecida por los distintos servicios penitenciarios que es inconstante y discrecional por sí misma. Un ejemplo tiene que ver con lo que puede o no puede entrar en las visitas. Las listas exhibidas en el habitáculo donde se hace la inspección cambian continuamente, de manera que se puede llevar al detenido algo que estaba permitido pero que, una semana más tarde, se

14 Nos han dicho que las "antiguas" celdas de castigo donde se mantiene al detenido o "engomado", según la jerga carcelaria (es decir, aislado como castigo puro y duro) se usan para resguardar a alguien problemático, ya sea por su conducta dentro de la cárcel o bien porque su delito cometido genera enojo. Esto sucede tanto en unidades de alta complejidad enclavadas en plena zona urbana como en unidades penitenciarias de muros abiertos donde las personas detenidas se auto-organizan, generalmente en zonas rurales. El sentido común prima también dentro de las cárceles, de manera tal que algunos delitos son repudiados, tal como lo hace la opinión pública en general Pero además hay una categorización de los delitos, por lo que, en algunos casos, el detenido entrante es bienvenido, como se ha dicho, y hasta admirado (como haber matado a un policía o a un agente de cualquier fuerza de seguridad, designado, como se dijo, con distintos nombres de vocabulario carcelario) lo tiene que llevar de vuelta porque ahora ya no lo está. El esfuerzo de las familias por tratar de complacer al detenido se ve defraudado, con lo que la voluntad y el ímpetu por «hacer» la visita va disminuyendo sobre todo en condenas largas. Una segunda clave, como se dijo, tiene que ver con una dimensión invisible, pero que se debe respetar a rajatablas, que es la establecida por los propios presos (en primer lugar entre ellos y luego en relación con el servicio penitenciario). Así, si el detenido no tiene visita propia, se lo invita a otra con el fin de hablar y escuchar, anoticiarse algo del afuera y hasta beneficiarse de enseres o víveres que han llevado al detenido visitado.

Ambos juegos de reglas no son compatibles, de manera que un detenido se puede ver más de una vez «preso» de las decisiones que va a tomar y debe elegir entre una u otra en una situación determinada. Para ello, sabe de antemano que cualquiera sea el camino que tome tendrá un castigo; la peor siempre será la prohibición de la visita seguida por el aislamiento, además de la pérdida de su puntaje para la eventual junta correccional.

Este asunto da pie a considerar nuevamente la posibilidad de que en este tipo de encierro se pueda generar una impostada actitud de apego a las normas, ya que en la vida libre hay, en general, más de una opción que se pueda elegir que no devenga en un castigo. Si bien los acuerdos sociales no son necesariamente producto de un consenso amplio, habrá una salida no sancionatoria. Se debe considerar que, en estos tiempos, tales consensos son establecidos cada vez entre menos personas, grupos o sectores frágiles en los países democráticos. Los conflictos tienen una escala que supera el nivel individual, por lo que las decisiones colectivas de la vida diaria se toman con un cierto respaldo. Por su propia definición, la cárcel impide estos caminos sinuosos y de mediano o largo plazo; al contrario, los hace directos e implacables.

En la resolución interlocutoria se dice que el detenido, que pide por voluntad propia el ejercicio de su derecho a la libertad condicional, ha tenido una vida previa al encarcelamiento difícil, situación que actuaría como una suerte de «atenuante». Aunque se suele hacer esta afirmación, por ahora no se puede tener certeza de la relación directa entre ambos factores. En general, los informes de las trabajadoras 
sociales, más que nada de los patronatos, ponen esta cuestión casi como definitoria; pero no se encuentran todavía explicaciones que confirmen la correspondencia entre sufrimiento, individual o colectivo y delito.

\section{CASO B}

En la evaluación de este detenido, prima el criterio de la voluntad, que se incluye bajo el término de «conducta», siendo el de «concepto» subsidiario. El mal comportamiento intramuros indicaría que aún no está preparado para la vida en libertad debido a que ha sido objeto de numerosas sanciones medias o graves. El interno no tendría la voluntad de iniciar una revisión crítica de su comportamiento y tampoco en relación con los numerosos ofrecimientos de un tratamiento psicológico.

Dado que en el ámbito de la conducta humana la generalización es riesgosa, ¿debería haber, quizá para casos «especiales», una «mirada externa» o una suerte de juicio independiente del servicio penitenciario?

No es posible ponderar el componente de subjetividad a la hora de emitir informes; entonces ¿cómo afirmar que cambió (o no) su matriz transgresora o directamente delictiva, fuera del «hacer conducta» para salir con los derechos que da la ley? Esto sin una mirada y puesta a punto situacional, independiente de quienes estuvieron acompañándolo en el transcurso carcelario durante el cual se generarán vínculos $\mathrm{y}$ emociones positivas, negativas o una mezcla de ambas (Liebling \& Maruna, 2005; Luhrmann, 2006).

Por nuestra experiencia con los penitenciarios, estas emociones se expanden y se comparten sin conseguir tomar distancia. Contar con una perspectiva desapegada de los avatares de la vida diaria sería un parámetro que podría considerarse «objetivo» hasta cierto punto, incluyendo los informes y teniendo en cuenta inconductas y sanciones. Es difícil contraponerse tanto a la opinión pública - con su pertinaz negativa y reemplazando el término «derechos que otorga la ley» por «beneficios» como si fuera una limosna jurídica - respecto de conceder los derechos que brinda la ley, que nunca son demasiado claros ni públicos como lo piensan quienes tuvieron a su cargo la vigilancia y el contacto diario en general, o quienes se acercaron desde sus especialidades.
Se convierten entonces en presos «fuertes», contrario al que suelen llamar "cachivache», alguien que se deja usar sin calcular la ecuación costo-beneficio. Esto es objeto de múltiples sanciones, ya que le «mandan a hacer» las cosas que los otros saben que implica sanciones disciplinarias en caso de incumplimiento. Pero, frente al servicio penitenciario, casi todos son obedientes y cumplen todas las órdenes impartidas para hacer su propia conducta después, en la hondura de los muros y las reglas carcelarias, encargando a los presos de «menor nivel» o que califican «bajo» en las escalas de los detenidos las tareas desagradables que son menospreciadas. Para ello los someten a servidumbre en todos los órdenes de la vida carcelaria. Al contrario, aparece como un preso modelo pero es en realidad otro, rebelde y poco compasivo. Nada de lo dicho en este párrafo tiene que ver con su futuro comportamiento. Siguen manteniendo una conducta ejemplar durante el encierro y encaran sus deberes de la mejor manera posible, siempre que sean visibles al servicio penitenciario. Cuando la pena ha sido cumplida en su totalidad y son «realmente» libres, la conducta futura es impredecible. La frustración, anudada a la imperiosa necesidad de establecerse en una posición social que se sobreponga a la que se tenía antes, genera un quiebre emocional y de la identidad que puede desembocar en caminos quizá no pensados ni queridos en el encierro carcelario o incluso durante la primera etapa de libertad condicional. Es debido a este plus que imponen las vicisitudes de la realidad cuando ya se está en libertad que la evaluación del tratamiento penitenciario es aproximativa. ${ }^{15}$

Siendo la cárcel una institución cerrada en estos tiempos, pero a la vez de límites porosos (es decir, influida por el afuera y que influye ella misma más allá de sus límites perimetrales),

15 Las evaluaciones psicológicas que se consideran para la "readaptación", o incluso el criterio de "peligrosidad" como pronóstico que subrepticiamente sigue vigente, son superficiales en tanto los propios psicólogos desconfian de los parámetros que deben utilizarse. Además, si no hubo un seguimiento pormenorizado, casi no conocen a quién están evaluando. Trabajan como parte de una mera rutina. Este punto no está demasiado enfatizado, dado que de dicha evaluación depende en buena medida una decisión a favor o en contra de otorgar determinadas libertades. En el lugar en que trabajamos y durante un largo tiempo, dicho análisis era hecho por un psiquiatra que exponia su punto de vista en un solo párrafo que solia repetir palabra por palabra. En una oportunidad en que fue objeto de un sumario administrativo, se constató que no había, en realidad, entrevistado al detenido. Había confeccionado su ya de por si escueto y hermético informe sin citarlo ni hablar con él. (Comunicación personal. La interlocutora solicitó anonimato, noviembre de 2014) 
mantiene una posición paradojal (Da Cunha, 2004). Recibe estímulos varios con la entrada de maestros, profesores, talleristas, familiares, representantes de distintas comunidades religiosas, y así. A la vez, actúa como una institución de encierro que desparrama su núcleo criminogénico en lugares como barrios, vecindarios, parajes, localidades e incluso tierras fiscales tomadas, donde fijan domicilio quienes tienen ya sus distintas libertades. La apertura criminogénica de la cárcel será siempre de signo negativo, ya que los lugares donde hay más de un integrante que lo haya sufrido son refugio no solo de quienes cometen delitos más o menos graves, sino también de los pequeños narcotraficantes, sus «cocinas» de cocaína y las consecuencias que generan sobre todo en los jóvenes. A estos últimos se les incita al reparto de pequeñas dosis de drogas, pagar en armas robadas, el inicio en la droga que se desecha y que mezclan con cualquier elemento tóxico, deserción escolar o profundización de la desintegración familiar. Estos son núcleos que originariamente fueron fundados como familias pero que ya han agotado todos sus recursos, por cierto escasos, de forma tal que, aunque sigan conviviendo en un mismo espacio, han desaparecido las distintas funciones que la caracterizan, así como el reparto de las diversas responsabilidades y montos de poder, hasta igualarse solo en el uso de la violencia. En estos barrios con altos índices de criminalidad y de vecinos que van y vuelven del delito y de la cárcel, se debilitan los controles informales, ejercidos por las instancias intermedias conformadas por sus miembros, cuestión que abre el paso a los controles formados, de manera que son supervisados y vigilados por las fuerzas de seguridad. Tienen gran movilidad porque algunas familias prefieren mudarse para tener un mejor futuro, sobre todo para sus hijos, y se instalan aquellas que ya han caído en el pozo de una trayectoria delictiva de uno o de varios de sus miembros.

\section{CONCLUSIONES}

Se debería intentar comprender críticamente las influencias estructurales que tienen las decisiones personales, tanto para el caso de desistimiento (definitivo o intermitente) o su contrario, la reiteración en el delito, así como la relación de estos posibles caminos con las motivaciones y opciones con que cuentan las personas. En este sentido, el fracaso del regreso conlleva aun a más violencia, que se transforma en estilos de vida completos que son interactivos y cuyas formas de quebrarse nos son por ahora conceptualmente opacos.

La pregunta que se impone es por el criterio de comparación entre las relaciones sociales mantenidas por la persona entre el contexto de libertad y el de encierro. Si bien han transcurrido por cursos de acción delictivos, o al menos de desapego a la ley escrita, y sus vidas han estado cargadas de sufrimiento al ser quizá víctimas y victimarios al mismo tiempo, aun así no podríamos construir un parámetro epistemológicamente viable para proceder con las comparaciones entre uno y otro contexto. La imposibilidad reside en el rasgo que impide elaborar cualquier criterio de comparación: la coerción penal/penitenciaria, la no elegibilidad de quienes van a convivir pocos o muchos años de sus vidas, la obligatoriedad de las rutinas diarias que se repiten en forma insidiosa pero que pueden cambiar de forma abrupta, sin justificación aparente o comunicada, sin medir tiempos o formas de adaptación, como en el caso de los traslados no solicitados, perdiendo el capital humano, material o simbólico que se haya podido acumular hasta entonces. Se empieza de cero una y otra vez; cada inicio es igual o peor a la primera entrada a la cárcel, y así sucesivamente en condenas largas sean cualesquiera las razones, usualmente por sanciones que implican mayor distancia con el núcleo familiar de apoyo. A mayor número de traslados, peores son las condiciones de adaptación y desmejoran sensiblemente la conducta hasta dejarla destartalada mientras que el proceso del pasaje por las diversas etapas de la llamada «rehabilitación» penitenciaria (mediante el proceso de progresividad) ha quedado en el cajón de algún escritorio por donde se deambuló.

Llegado el momento de la evaluación para precisar si se está en condiciones de alguna de las libertadas dispuestas en la Ley de Ejecución Penal vigente, cualquier pronóstico referido a la forma en que tomarán los vínculos en libertad tendrá que estar relacionado con cómo se configuraron dos ámbitos incompatibles dentro de la cárcel.

Bajo tal fin, sería posible referirse a distintos tipos de contextos: el de la ofensa, el carcelario y el de la reintegración. 
El «contexto de la ofensa» se refiere a la interrelación entre conocimiento y habilidad para conducirse de acuerdo con él y los límites que las instituciones sociales imponen a las acciones concebidas a partir de nuestros conocimientos. Este complejo entramado depende, a la vez, de la propia posición en la estructura social. Cuanto mayor sea la capacidad de adquirir conocimiento, cuanto mayor sea la cantidad de esas fuentes, cuanto más flexibles sean los límites institucionales para que permitan innovaciones en las acciones individuales, menor será la posibilidad de cometer o reincidir en el delito (Birbeck, 2003; Colmenarez Isturiz, 2005; Leverentz, 2001).

Este contexto también se refiere a la constelación más amplia en donde se produce el hecho delictivo. No solo incumbe a las características específicas referidas al estado psíquico del imputado y al recuento de la sucesión de acontecimientos, sino al conjunto total de su cosmovisión. Esta última no empieza ni termina en el hecho consumado, sino que es anterior y continuará después de él (Maruna, 2001).

El «contexto carcelario» está caracterizado por su hermetismo, coerción, anulación del libre albedrío y capacidad de quebrar la identidad. Los internos tienen como denominador común la violencia, la imposibilidad de protestar, la falta de movilidad física sin permiso previo y un conjunto completo de prohibiciones que suelen cambiar sin aparente coherencia o razonabilidad. Por eso, la frecuencia de las visitas, el estímulo por participar en alguna de las actividades que se ofrecen (siempre escasas), la lectura o actividades recreativas o estéticas, la religión, la televisión y revistas que puedan ingresar los mantiene, en alguna medida, en contacto con una realidad a la que deberán volver. Este momento causa un importante caudal de incertidumbre y ansiedad, a pesar de haber mantenido algunos de los vínculos antes citados.

En tanto que en el «contexto de reinserción»» las exigencias dependen de la conducta y el concepto carcelarios. Como hay una escala graduable de salidas, desde las de corto tiempo hasta la libertad condicional, podrían ser evaluadas en sus resultados como otra fuente de información para conceder o denegar la libertad condicional. Tal medida daría indicadores interesantes debido a que son instancias de prueba, un ítem que por ahora parece desconocerse.
La vuelta a la sociedad implica un nuevo inicio en peores condiciones. Se arrastra el sello carcelario que, por más resistencia que se le haya opuesto, deja restos que quizá seguirán estando en el resto del recorrido vital de las personas en forma de «estigma» o «etiquetamiento», como si los barrotes de la cárcel se hubieran quedado impresos en él como una delación sinfín.

Delante está la libertad, aquella soñada y planificada en su más mínimo detalle durante el tiempo carcelario, pero inasible en libertad como si fuera una abstracción que no se puede alcanzar. En ciertos casos, esta no se logra asir sobreviniendo como en un mal sueño el ciclo carcelario.

\section{REFERENCIAS BIBLIOGRÁFICAS}

Añez Castillo, M. A., Han Chen, L., Morales Manssur, J. N. \& Párraga Meléndez, J. (2008). Asistencia laboral penitenciaria y post penitenciaria una propuesta a la reintegración social del recluso. En: Capítulo Criminológico, 36 (4), pp. 51-88.

Birbeck, Ch. (2003). El desempeño penal bajo el destacamento de trabajo en la región andina de Venezuela (1999-2002). En: Capítulo Criminológico, 31 (4), pp. 33-74.

Bosworth, M. \& Carrabine E. (2001). Reassessing resistance: Race, gender, and sexuality in prison. En: Punishment \& Society, 3 (4), pp. 501-515.

Cesano, J. D. (2009). La ejecución de la pena privativa de la libertad. Una lectura desde la perspectiva del Derecho Internacional de los Derechos Humanos. Ed. Pontificia Universidad Javeriana, Colección Internacional: Bogotá, p. 41 y ss.

(2008). Contribución al estudio de la libertad condicional (análisis dogmático y político criminal de acuerdo a la reforma de la ley 25.892). Córdoba: Editorial Mediterránea, p. 208

(2004). Beneficios penitenciarios y ley aplicable. A propósito de un fallo del Tribunal Constitucional de Perú (algunas reflexiones dogmáticas y una perspectiva iuscomparativa). En: Revista Peruana de Jurisprudencia. Trujillo: Normas Legales Editora. 2004, V (37), pp. 387-402. 
(2002). Concesión de la libertad condicional. Observancia de los reglamentos y calificación de concepto. Ed. Mediterránea: Córdoba, pp. 86-87.

Clear, T. \& Ryder, J. (2001). Incarceration and the Community: The Problem of Removing and Returning Offenders. En: Crime \& Delinquency, 47 (3), pp. 335-351.

Código Penal de la Nación Argentina T.O. (1984). Ministerio de Justicia y Derechos Humanos, República Argentina.

Colmenarez Isturiz, J. (2005). Actitud familiar ante la llegada del liberado al hogar (estudio de casos). En: Capítulo Criminológico, 33 (1), pp. 79-113.

Colombo, Marcelo (2004). Libertad asistida. Un análisis sobre las condiciones para su otorgamiento y la dudosa constitucionalidad de la regla que habilita su rechazo. En Cuadernos de Doctrina y Jurisprudencia Penal, Año IX, N. ${ }^{\circ} 17$

Comfort, M. (2002). The «Papa's house». The prison as domestic and social satellite. En: Ethnography, 3 (4), pp. 467-499.

Crewe B., Warr J., Bennett P. \& Smith A. (2013). The emotional geography of prison life». En: Theoretical Criminology, 18 (1), pp. 56-74.

Da Cunha, M. (2004). El tiempo que no cesa. La erosión de la frontera carcelaria. En: Renglones, 9 (1), pp. 58-59, 32-40.

Foucault, M. (1990). La vida de los hombres infames. Buenos Aires: Ediciones de La Piqueta, p. 220.

Garland, D. (2005). La cultura del control. Crimen y orden social en la sociedad contemporánea. España: Gedisa, p. 472.

Hammett, Th., Roberts, Ch. \& Kennedy, S. (2001). Health- Related Issues in Prisoner Reentry. En: Crime \& Delinquency, 47 (3), pp. 390-409.

Harding, D. (2003). Jean Valjean's dilemma: the management of ex- convicts identity in the search for employment. En: Deviant Behaviour, 2003, 24 (1), pp. 571-595.

Hassemer, W. (1984). Fundamentos del Derecho Penal, Barcelona: Ed. Bosch, p. 428.
Hollin, Clive (2011). Voz. «Determinismo». En Eugine MCLaughlin y John Muncie (compiladores). Diccionario de Criminología, Gedisa Editorial: Barcelona, pp. 194-195

Hood, R. \& Sparks, R. (2006). Problemas clave en criminología. Madrid. Guadarrama, p. 255

Kalinsky, B. \& Cañete, O. (2010). Madres frágiles. Un viaje al infanticidio. Buenos Aires: Editorial Biblos, p. 141.

(1997). La piel de cordero. Una metáfora para la acción individual. En: Vertex, Revista Argentina de Psiquiatría, (28), pp. 145-149.

Leverentz, A. (2001). Neighbourhood context of attitudes toward crime and re-entry. En: Punishment \& Society, 13(1), pp. 64-92.

Ley 24.660 de Ejecución de la Pena Privativa de la libertad de la República Argentina (1996). Ministerio de Justicia y Derechos Humanos, República Argentina.

Liebling, A \& Maruna, Ch. (2005). The effects of imprisonment. Londres: William Publishing.

López, Axel y Machado, Ricardo (2004). Análisis del régimen de ejecución penal. Fabián J. Di Plácido (editor). Buenos. Aires, p. 183 y ss.

Luhrmann, T. (2006). Subjectivity. En: Anthropological Theory, (6) 3, pp. 48-59.

Marchetti, A. M. (2002). Carceral impoverishment. Class inequality in the French penitentiary. En: Ethnography, 3 (4), pp. 416434.

Maruna, Sh. (2001). Re-entry as a rite of passage. En: Punishment \& Society, 13 (1), pp. $13-28$

Messuti, A. (2001). El tiempo como pena. Buenos Aires: Campomanes.

Núñez, G. (2005). Las fórmulas alternativas de cumplimiento de pena en el sistema penitenciario venezolano. En: Capítulo Criminológico, 33 (1), pp. 31-53.

O'Brien, P. (2001). Making it in the «Free World», Women in transition from prison. State University of New York Press, p. 201 
Pérez Arias, José y Novoa Rodríguez, Karina (2007). Libertad asistida industria Argentina. En: Revista de Derecho Penal y Procesal Penal, N. ${ }^{\circ}$ 7. Ed. Lexis Nexis, Bs. As., p. 1291

Recurso de casación, Sentencia N. ${ }^{\circ}$ XXX/94 (2000). En Adriana T. Mandelli, Doctrina Judicial. Córdoba: Ed. Mediterránea, p. 325.

Richie, B. (2001). Challenges Incarcerated Women Face as They Return to Their Communities: Findings from Life History Interview. En: Crime \& Delinquency, 47 (3), pp. 368-389.

Robinson, G. (2008). Late- modern rehabilitation. The evolution of a penal strategy. En: Punishment \& Society, 10 (4), pp. 429-445.

Rodríguez, M. N. (2006). Hacia una reinterpretación de la reinserción social en el contexto de los derechos humanos: la experiencia uruguaya. En: Debates Penitenciarios, 5, pp. 3-12.

Scott, G. (2004). «It's a sucker's outfit» How urban gangs enable and impede the reintegration of ex- convicts. En: Ethnography, 5 (1), pp.107-140.
Silva Sánchez, J. M. (2002). El retorno de la inocuización: El caso de las relaciones jurídico penales frente a los delincuentes sexuales violentos en derecho comparado. En: Redondo Santiago (coord.). Delincuencia sexual y sociedad. España: Ariel, pp. 85-102.

Surrat, H. (2003). Parenting attitudes of druginvolved women inmates. En: The Prison Journal, 83 (2), pp. 206- 220.

Wacquant, L. (2000). Las cárceles de la miseria. Buenos Aires: Ediciones Manantial, p. 390

Wheeler, S. (2007). Socialization in correctional communities. En: British Psychological Review, 15 (26), pp. 267-282.

Zaffaroni, E. R. (1992). Hacia un Realismo Jurídico Penal Marginal. Caracas: Monte Ávila Editores, p. 366. 